\section{The Television Cable}

IN the Engineering Supplement to the Siemens Magazine of June, Mr. A. Rosen describes the London television cable which joins the Alexandra Palace studio to Broadcasting House and goes thence to the Whitehall Telephone Exchange. Success is being achieved and provincial cities are looking forward to having broadcast television services. It is probable that eventually there will be a network of television cables interconnecting the studios and transmitters throughout the country, similar to the grid of the programme circuits which now exists for sound broadcasting. Television is analogous to telephony. In telephony the voice sounds are converted by the microphone into equivalent alternating currents; these are transmitted to the receiving loud-speaker, where they are converted back to the voice sounds. Similarly the, visual image is converted by the television camera into equivalent electric currents which are carried to the receiver where the cathode ray tube converts them back to the visual image. In both cases the transmission between sender and receiver can be effected over a metallic circuit, or by a radio link or by a combination of the two methods.

THE chief points of difference between the two transmissions concern the band of frequencies which have to be transmitted. In telephony, for music it suffices to transmit currents of frequency lying between 50 and 10,000 cycles to get excellent results. The television camera generates a much wider band of frequencies. In the Marconi-E.M.I. system, the frequencies range from zero to more than two million cycles. This necessitates the use of a correspondingly high carrier frequency for radio television transmission. The B.B.C. is to be congratulated on its notable achievement in televising the Coronation procession. This was the first successful high-definition relay in the world. The E.M.I. and Siemens gave valuable assistance to the B.B.C. in carrying out this enterprise. The author states that for trustworthy transmission between points more than 25 miles apart cables are necessary. Radio links also are liable to be affected 'by 'man-made' disturbances such as the radiations produced by the ignition systems of motor cars.

\section{The Electrification of the Rigi Railway}

IT is now sixty-six years ago since the first rack railway in Europe, the Rigi railway, between Vitznau on the Lake of Lucerne and the top of the Rigi, was opened. It will be electrified in the autumn of the present year and will be brought into line with the latest modern requirements. The new motor-coaches will be light and comfortable, and the increase in speed will shorten the trip considerably. Fewer employees will be required as the preliminary work done in starting up the steam locomotives will be done away with and because it is easier to supervise electric vehicles. One-man control also suffices in the motor-coaches. When peak track conditions occur some of the existing steam locomotives can be used, and these are kept as a useful stand-by. The electric equipment of the motor-coaches will be built by Brown, Boveri and Co., Ltd., Baden, while the mechanical part and coachwork will be constructed by the Swiss Locomotive Works at Winterthur. Direct current will be used at a pressure of 1,500 volts and the average running speed will be about nine miles per hour. On the up-grade, the highest running speed is about eleven miles an hour and on the downgrade about seven miles an hour. The difference in altitude between the Vitznau and Rigi Kulm stations is about 4,300 feet, and the steepest gradient is 25 per cent. In the Brown Boveri Review of March, diagrams of the new coaches are shown. The braking devices comprise electric resistance braking as service brake on the down-grade and two hand brakes independent of one another and actuated by spindle from either driver cab. When the brake is applied on the up. grade it prevents the coach running backwards should the current fail. There is also an overspeed brake which operates on a brake drum on the motor and only acts on down-grade running. In emergencies it is put into action by a safety device.

\section{The House-Rat in the United States}

ALтнобgH the black rat (Rattus rattus) still predominates in the southern States, particularly in Florida and the States bordering the Gulf of Mexico, throughout the States in the temperate zone it has been displaced by the brown rat (Rattus norvegicus), which appears to have been introduced about the beginning of the American Revolution, in 1775. Now the rat population is enormous-in Texas some years ago 153,720 rat tails were collected in six weeks; in Georgia, Alabama and Texas during the typhus fever control campaign in 1934, it was estimated that $7,500,000$ rats were destroyed on 747,608 premises treated, or approximately two rats for every person living on the premises. The total economic damage done by these pests is enormous. In the course of one of its inquiries, the Biological Survey received 14,650 replies from farmers co-operating in rat campaigns, and the annual losses therein reported averaged 35 dollars a farm, while a computation of the grand total of loss throughout the United States each year is 189 million dollars. In addition, rats are seriously concerned in the conveyance of certain diseases among human beings and domestic stock, and in an effort to arouse co-operative measures of ratcontrol, the U.S. Department of Agriculture has published an eighteen-page circular (No. 423, Jan. 1937) on "The House Rat"

\section{Migrations of Salmon}

AT a meeting of the Washington Academy of Sciences held recently, a discussion on the homing migrations of salmon was opened by prof. Henry $B$. Ward. According to a report by Science Service, of Washington, D.C., he said that the return of salmon, generation after generation, to their ancestral breeding grounds, is a response to definite stimuli, amongst which he regards temperature as being the most powerful. Swiftness of current has also some effect in guiding the fishes, although relative acidity of the water seems to have no influence. But if it be 